\title{
Emblemas da ciência nacional
}

\author{
Symbols of Brazilian science
}

\author{
Insignias de la ciencia nacional
}

\begin{abstract}
MANGUINHOS DO SONHO À VIDA: A CIÊNCIA NA BELLE ÉPOQUE. Benchimol JL, coordenador. Rio de Janeiro: Editora Fiocruz; 2020. 320 p. ISBN: 978-65-5708-023-8.
\end{abstract}

doi: 10.1590/0102-311X00044321

Em um dos seus mais conhecidos livros, Starobinski 1 reportou-se à contingência de nos apoiarmos em emblemas para idealizar e concretizar nossos projetos, lembrando que emblemas são constituídos por representações de construções mentais, de personagens humanos e de itens da natureza e da cultura material. No que se refere às ciências brasileiras, dois emblemas se entrelaçam a ponto de só poderem ser entendidos conjuntamente: Oswaldo Cruz e a sua principal criação, o Instituto de Manguinhos, que em 1907 foi rebatizado com o seu nome.

O livro em tela se debruça sobre esses dois símbolos da cultura brasileira, situando o criador e a criatura como elementos representativos da modernidade científica nacional no período da Belle Époque. Benchimol e a equipe que ele coordenou enveredaram por extensas coleções de documentos, textos memorialísticos, aparatos laboratoriais e desenhos e plantas arquitetônicas. Além disso, dialogaram com uma bibliografia ampla, sem no entanto se deixarem seduzir pelos tons sacralizadores que impregnam os ensaios biográficos sobre Oswaldo Cruz, tramados por seus discípulos diretos e admiradores 2,3 , as des- crições em tudo bucólicas da Região de Manguinhos na abertura do século passado $4 \mathrm{e}$ as análises burocratizadas das atividades desenvolvidas pelo Instituto 5. Em vez disso, a obra capitaneada por Benchimol associou a acuracidade necessária para a elaboração de uma pesquisa histórica de qualidade a um olhar sensível à instituição e aos indivíduos que a ela deram vida.

As balizas temporais adotadas no livro foram o ano de 1900, quando foi criado o Instituto de Medicina Experimental, conhecido como Instituto de Manguinhos e, 1937, quando o Instituto Oswaldo Cruz já se apresentava fragilizado a ponto de se tornar presa fácil de intensa intervenção por parte da burocracia estado-novista. Entre uma e outra data, a instituição vivenciou períodos díspares, sendo o primeiro deles pautado por significativo grau de autonomia conquistada por Oswaldo Cruz, que dirigiu o que ele denominava "jardim da infância da ciência". Além de pesquisador, formador de quadros, sanitarista e administrador, o médico era também um hábil negociador junto à esfera política, conseguindo verbas e garantindo a liberdade necessária para que seus subordinados pudessem desenvolver pesquisas que permitiram que a ciência nacional ganhasse prestígio no contexto internacional. A instituição também padecia de limites, sendo o principal deles o poder acumulado tanto pelo diretor quanto pelos cientistas que dominavam cada serviço ou laboratório do Instituto. A admissão de novos funcionários dependia da aprovação de Oswaldo Cruz e cada chefe de seção desfrutava da liberdade de decidir sobre a pato- 
logia que iria pesquisar, prática que começava a cair em desuso na Europa e nos Estados Unidos.

Após a morte de Oswaldo Cruz, ocorrida em 1917, seus sucessores na direção de Manguinhos não se mostraram capazes o suficiente para obter as verbas necessárias para garantir a continuidade da excelência da produção científica, o que causou a debandada de parte de seus mais destacados pesquisadores, agravando com isto a situação de declínio do Instituto. Nesses quadros, a problemática que orienta o livro mostrase pontuada por uma questão já antes assinalada por Stepan 6: as condições em que se praticava ciência de qualidade em um país postado às margens dos grandes fluxos de capitais.

Paralelamente ao enfoque das atividades, o Instituo foi também vistoriado sob a dimensão de um espaço físico criado especialmente para o desenvolvimento das atividades científicas. Nesse tópico, o leitor acompanha detalhadamente as transformações impostas ao ambiente natural da Fazenda de Manguinhos, do pântano que a separava do mar e a edificação das primeiras instalações patrocinadas pelo Instituto, conferindo destaque especial ao Pavilhão Mourisco, idealizado por Oswaldo Cruz e baseado, especialmente em seu aspecto externo, no palácio-fortaleza de Alhambra, construído no século XIV pelos ocupantes árabes da cidade espanhola de Granada, sendo que seu interior foi concebido como um espaço moderno e viável para o desenvolvimento das pesquisas científicas. A transposição do sonho para a realidade fez com que o prédio principal do Instituto passasse a ser de imediato um ícone da arquitetura carioca, persistindo até hoje como símbolo da Fundação Oswaldo Cruz (Fiocruz) e também como uma construção de referência na cidade do Rio de Janeiro.

Após registrar as técnicas de construção adotadas e a origem dos materiais utilizados nas edificações, a maior parte deles importada da Europa, o enfoque do livro é desviado para a implantação dos serviços de pesquisa em cada um dos ambientes dos edifícios, assim como a aquisição dos equipamentos necessários para cada um dos laboratórios. Graças às verbas oficiais e também aos recursos provenientes da venda de produtos biológicos elaborados pelo próprio Instituto, foi possível a aquisição dos recursos laboratoriais mais aprimorados disponíveis nas primeiras décadas do século passado, pois tinha-se em vista que os avanços científicos só poderiam ocorrer quando houvesse ambientes apropriados e em laboratórios equipados e não nos acanhados espaços e nos laboratórios ultrapassados que existiam nas faculdades de medicina, inclusive a localizada no Rio de Janeiro.

O último tópico do livro é dedicado ao engenheiro-arquiteto que soube transformar em realidade os edifícios vislumbrados por Oswaldo Cruz. Raramente referenciado na bibliografia sobre Manguinhos, o português Luís de Morais Júnior chegou no Brasil como contratado para recuperar a instalação de uma igreja carioca e, graças a um encontro casual com Oswaldo Cruz, tornou-se o principal agente de planejamento de plantas e construções hospitalares da antiga capital da República. Sua arquitetura eclética marcou o período no qual a cidade do Rio de Janeiro sofreu a intervenção modernizadora, apesar de que atualmente são poucas as obras planejadas por Morais Júnior que sobreviveram à sanha destruidora do que é considerado "antigo".

$\mathrm{O}$ enfoque oferecido pela obra referente à história da atuação do Instituto, à construção de seus prédios e ao engenheiro encarregado das obras não se restringiu ao aspecto descritivo. Em seus interstícios, o autor apontou uma série de questões que estavam ainda para ser melhor respondidas, constituindo uma espécie de agenda a ser explorada pelos então jovens pesquisadores de um órgão nascente na Fiocruz, a Casa de Oswaldo Cruz que, no decorrer dos anos, transformou-se em um dos principais polos de renovação da história das ciências do país. Credita-se ao que foi indicado por Benchimol a produção de um número significativo de pesquisas inovadoras no campo do saber médico e da saúde pública, mencionando-se dentre elas as respostas oferecidas àqueles que ainda teimam em avaliar a atuação de Oswaldo Cruz como uma mera cópia tropical dos feitos de Pasteur 7,8 e o conhecimen- 
to mais abrangente do Brasil devido ao trabalho dos sanitaristas 9,10 .

A reedição do livro coordenado por Benchimol constitui uma reimpressão comemorativa dos 30 anos do seu lançamento original e reitera a importância de um Instituto que, desde os momentos iniciais, é protagonista de uma história pautada por conquistas científicas, mas também por uma contínua luta contra a escassez de verbas e tentativas de ingerência política espúrias. Ler este livro é lembrar a importância de dois emblemas fundamentais da ciência brasileira, atitude salutar neste momento pautado por desafios em série, quer no plano político, quer no contexto ferido por uma pandemia avassaladora.

\section{Cláudio Bertolli Filho ${ }^{1}$}

1 Faculdade de Arquitetura Artes e Comunicação de Bauru, Universidade Estadual Paulista Júlio de Mesquita Filho, Bauru, Brasil.

cbertolli@uol.com.br.

\section{Informação adicional}

ORCID: Cláudio Bertolli Filho (0000-0003-35849736).

1. Starobinski J. 1789 - os emblemas da razão. São Paulo: Companhia das Letras; 1989.

2. Sales Guerra E. Osvaldo Cruz. Rio de Janeiro: Vecchi; 1940.

3. Fraga C. Vida e obra de Oswaldo Cruz. Rio de Janeiro: José Olympio/Insituto Nacional do Livro; 1972.

4. Dias EC. O Instituto Oswaldo Cruz: resumo histórico, 1889-1918. Rio de Janeiro: Tipografia do Instituto Oswaldo Cruz; 1918.

5. Fonseca Filho O. A Escola de Manguinhos: contribuição para o estudo do desenvolvimento da medicina experimental no Brasil. In: Falcão EC, organizador. Oswaldo Cruz Monumenta Histórica. Tomo II. São Paulo: s.n.; 1973.

6. Stepan N. Gênese e evolução da ciência brasileira: Oswaldo Cruz e a política de investigação científica e médica. Rio de Janeiro: Artenova; 1976.

7. Brito N. Oswaldo Cruz: a construção de um mito na ciência brasileira. Rio de Janeiro: Editora Fiocruz; 1995.

8. Cukierman H. Yes, nós temos Pasteur: Manguinhos, Oswaldo Cruz e a história da ciência no Brasil. Rio de Janeiro: Relume-Dumará; 2007.

9. Lima NT. Um sertão chamado Brasil. 2a Ed. São Paulo: Hucitec Editora; 2013.

10. Hochman G. A era do saneamento: as bases da política de saúde pública no Brasil. 3a Ed. São Paulo: Hucitec Editora; 2012. 